Submission ID: 43825

\title{
Geological Chance of Success Estimation for Appraisal Objects in Western
} Siberia

A.S. Meshcheryakova* (LLC Gazpromneft NTC), M.G. Dymochkina (LLC Gazpromneft NTC), D.A. Kotunov (OAO Slavneft-Megionneftegaz)

\section{SUMMARY}

As known, planning geological prospecting works occurs under conditions of high uncertainty, i.e. lack and inaccuracy of information about the object of research. Concerning, the geological exploration process is very risky, and it is necessary to estimate risks and systematically manage them.

A systematic approach to the geological risks analysis and their permanent analysis is important for increasing efficiency of the exploration program and improves economic performance.

The main tool for geological risk estimation is the geological coefficient of success ( $\mathrm{gCoS}$ ). As the result of world experience analysis in our company, the methodology estimation of geological coefficient of success designed. However, for a correct assessment is required to collect gCoS statistics for different evaluation objects and compare it with the actual results.

In order to approbate the assessment methodology and to calibrate it, an evaluation of exploration and prospecting drilling objects for the coming years ware made. After comparison of the current assessment and results, it will be possible to optimize our approaches to estimating the geological coefficient of success. 


\section{Оценка коэффициента геологического успеха для поисковых объектов в Западной Сибири}

А.С. Мещерякова* (ООО "Газпромнефть НТЦ"), Дымочкина М.Г. (ООО "Газпромнефть НТЦ"), Д.А. Котунов (ОАО "Славнефть-Мегионнефтегаз")

\section{Введение}

Как известно, планирование геологоразведочных работ (ГРР) происходит в условиях высокой неопределенности, т.е. недостатка и неточности информации об объекте исследований. В связи с этим, геологоразведочный процесс весьма рискован, и необходим инструмент, позволяющий учитывать риски и системно управлять ими.

Системный подход к анализу геологических рисков и их непрерывный анализ играет важную роль в повышении эффективности программы ГРР, а также позволяет улучшить экономические показатели.

Основным инструментом учёта геологического риска, является оценка шанса геологического успеха $(\mathrm{gCoS})$, методика оценки которого успешно применяется в Газпромнефть НТЦ при оценке новых активов. Достоверным подтверждением прогноза шанса геологического успеха является проведение реальных геологоразведочных работ и получение фактических данных по объектам исследования.

С целью апробации методики оценки и её калибровки выполнена оценка объектов поисковоразведочного бурения на ближайшие годы. В результате сопоставления текущей оценки и результатов ГРР станет возможным оптимизировать наши подходы к оценке шанса геологического успеха.

\section{Метод и Теория}

gCoS (Geological Chance of Success) или шанс геологического успеха - это вероятность с которой произойдет открытие залежи, оцениваемая с учётом всех существующих неопределенностей. Сумма коэффициентов геологического риска $(\mathrm{gCoS})$ и геологического риска $(\mathrm{Rg})$ равна единице.

Шанс геологического успеха оценивается для ресурсов и определяет с какой вероятностью они могут стать запасами, т.е. применим только для поисковых объектов. $\mathrm{gCoS}$ применяется для оценки объема ресурсной базы (перспективной структуры, лицензионного участка, поисковой зоны), для оценки вероятности открытия (отдельного пласта, перспективной структуры, лицензионного участка, поисковой зоны), при построении дерева решений проекта.

Существует несколько методик оценки рисков, которые различаются, в основном, количеством факторов, определяющих итоговое значение gCoS. Различные источники (AAPG, CCOP, TOTAL, USGS и др.) выделяют от 4 до 7 факторов. В нашей компании принята методика аналогичная AAPG, которая включает 5 основных факторов (П. Роуз, 2011) (Рисунок 1):

1) Нефтематеринская порода и её зрелость (Рнм);

2) Пути миграции (Рм);

3) Наличие коллектора (Рк);

4) Наличие покрышки и сохранность (Рп);

5) Наличие ловушки (Рл).

$\mathrm{g} \operatorname{CoS}$ равен произведению независимых признаков.

$$
\text { gCoS }=P_{\text {нп }} \times P_{M} \times P_{K} \times P_{r} \times P_{c}, \text { где }
$$

Рнм - нефтематеринская порода и её зрелость; Рм - пути миграции; Рк - наличие коллектора; Рп - наличие покрышки; Рл - наличие ловушки. 


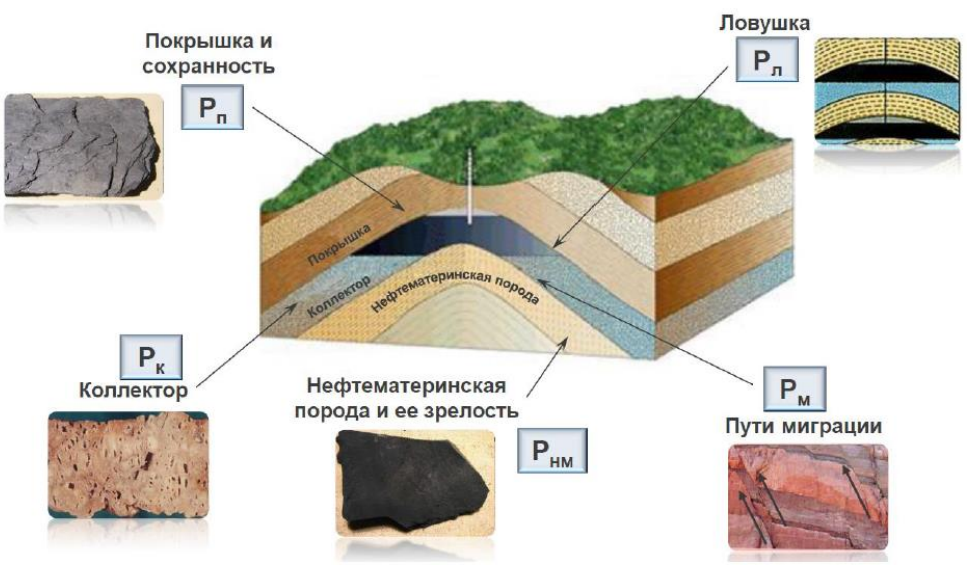

Рисунок 15 факторов

Каждый коэффициент оценивается по шкале от 0 (признак полностью отсутствует) до 1 (признак присутствует). В случае отсутствия информации, позволяющей подтвердить или опровергнуть наличие признака, коэффициент будет равен 0.5 (Рисунок 2). Для оценки каждого коэффициента существуют специальные матрицы (Dr. Shang-Yup Kim et. all, 2000).

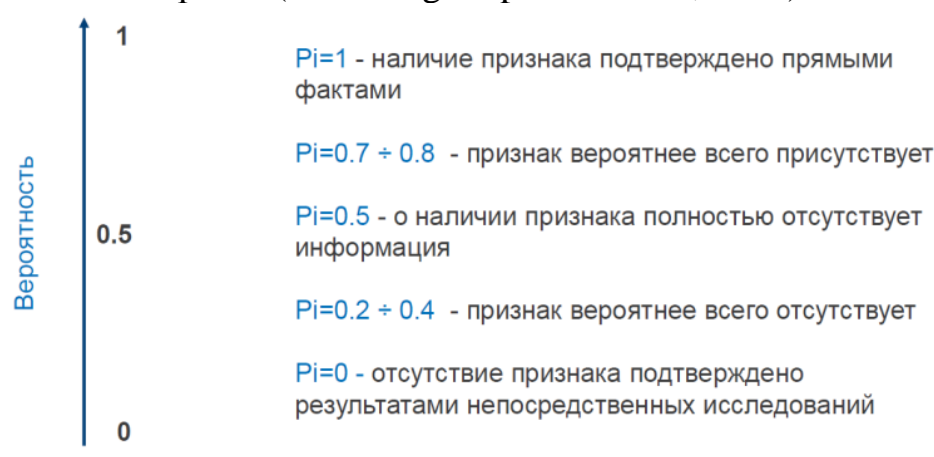

Рисунок 2 Шкала оченки вероятности наличия факторов риска

Между факторами может существовать полная или частичная зависимость, которую необходимо учитывать при расчете. Зависимость рисков влияет на значение gCoS, а значит на прогнозные ресурсы. Её необходимо учитывать при планировании мероприятий ГРР, что позволяет оптимизировать затраты на ГРР. Например, подтвердив наличие покрышки в 1 скважине мы подтверждаем её наличие для всех зависимых объектов.

\section{Пример}

Рассматриваемая территория расположена в ХМАО. По нефтегеологическому районированию территория относятся к Вартовскому нефтегазоносному району (НГР) Среднеобской нефтегазоносной области (НГО). В тектоническом плане территория приурочена к сочленению Нижневартовского мегасвода и Юганской мегамвпадины.

На рассматриваемой территории открыто 9 месторождений с залежами в верхнеюрском и нижнемеловом комплексах. Они послужили основными аналогами при вероятностной оценке.

Вся рассматриваемая территория покрыта СРР ЗД. В результате совместной переобработки и переинтерпретации нескольких кубов СРР ЗД был выявлен ряд перспективных объектов в мелководно-морских отложениях неокома БВ3, БВ4, БВ5 и верхнеюрском мелководно-морском пласте Ю1-1. 
По описанной методике шанс геологического успеха был оценен для 2 перспективных объектов (Рисунок 3). Чем больше перспективных объектов в районе 1 ловушки, тем выше общий шанс геологического успеха, т.е. вероятность получить УВ хотя бы в одном из пластов. Например, для ловушки 1 общий $\mathrm{gCoS}$ для четырех объектов равен 0.66 , в то время как $\mathrm{gCoS}$ для ловушки 2 равен 0.34 .

\begin{tabular}{|c|c|c|c|c|c|c|c|}
\hline Объект & Пласт & Рнп & Рм & Pк & Рл & Pc & gCos \\
\hline \multirow{4}{*}{ Ловушка1 } & БВ3 & 1 & 0.7 & 0.8 & 0.6 & 0.5 & 0.13 \\
\hline & БВ4 & 1 & 0.7 & 0.8 & 0.6 & 0.5 & 0.12 \\
\hline & БВ5 & 1 & 0.6 & 0.8 & 0.6 & 0.4 & 0.08 \\
\hline & Ю1-1 & 1 & 0.8 & 1 & 0.8 & 0.8 & 0.51 \\
\hline gCoS общий Ловушки 1 & & & & & & & 0.66 \\
\hline gCoS общий Ловушки 2 & БB5 & 1 & 0.8 & 1 & 0.7 & 0.6 & 0.34 \\
\hline $\begin{array}{c}\mathrm{gCoS} \text { общий ловушки } 1 \text { и } \\
\text { ловушки } 2\end{array}$ & & & & & & & 0.78 \\
\hline
\end{tabular}

Рисунок 3 Шанс геологического успеха для ловушки 1 и ловушки 2

•Вероятность наличия нефтематеринской породы (НMT)

Основной НМТ района работ является баженовская свита, выдержанная по площади и имеющая региональное распространение. Её отложения представлены глинистыми породами, обогащенными органическим веществом $(\mathrm{OB})\left(\mathrm{C}_{\text {орг }} 8-15 \%\right.$ до 22\%). ОВ зрелое, аквагенное, обогащённое керогеном I типа, $\mathrm{MK}_{1}{ }^{1}-\mathrm{MK}_{1}{ }^{2}$.

•Вероятность наличия путей миграции

Пласт $\mathrm{Ю}_{1}{ }^{1}$ является основным нефтесодержащим объектом на рассматриваемой территории. По СРР ЗД выявлены «зоны дезинтеграции». Ловушки были сформированы на начало миграции. Для пласта $Ю_{1}{ }^{1}$ характерна вертикальная миграция без барьеров.

Для пластов группы БВ3-5 характерна вертикальная миграция с барьерами. БВ5 наиболее рискован, т.к. рассматриваемая территория расположена на относительно пониженном участке Нижневартовского свода, нижележащий пласт БВ6 повсеместно водонасыщен в данном районе. Для пластов группы БВ характерна вертикальная миграция с барьерами (в западной части территории нижележащие пласты БВ7-8 заглинизированы). Ловушки сформированы до начала миграции.

•Вероятность сохранности УВ

Ловушка 1 пласта $Ю_{1}{ }^{1}$ - структурно-литологическая. Покрышка - баженовская свита. На имеющихся материалах и информации о строении соседних месторождений нет оснований для нарушения целостности покрышки.

Ловушка 2 пласта $\mathrm{Ю}_{1}{ }^{1}$ - комбинированного типа. Ограничена разломом, линией глинизации и предполагаемым ВНК. Покрышка - баженовская свита. Покрышка присутствует и нет предпосылок для нарушения её целостности.

УВ из ловушки 1 в пластах БВ3-5 могли мигрировать вверх по структуре. При этом в окружении присутствуют залежи в малоамплитудных и небольших по площади локальных поднятиях. Покрышки представлены региональными пачками глин.

•Вероятность наличия коллектора 
Для пласта $Ю_{1}{ }^{1}$ в аналогичных объектах, разбуренных на данной территории выявлены залежи нефти. Прогноз по СРР ЗД подтверждает наличие Нэф. Для пластов группы БВ характерна высокая неоднородность коллектора по площади. Прогноз по СРР ЗД подтверждает наличие Нэф.

\section{•Вероятность наличия ловушек}

Ловушка 1 приурочена к локальному поднятию. Амплитуда больше погрешности СРР 3 Д. Ловушка 2 приурочена к склону поднятия, амплитуда ловушки больше погрешности СРР. Для пластов БВ характерны залежи в малоамплитудных поднятия, амплитуда сопоставима с погрешностью СРР. Для неокомский комплекс имеет унаследованность структурного плана, характерная для всей территории, позволяет предполагать их существование.

В результате было получено распределение ресурсов с учетом и без учета gCoS (Рисунок 4). После изучения объектов можно будет сделать вывод о корректности принятых коэффициентов.

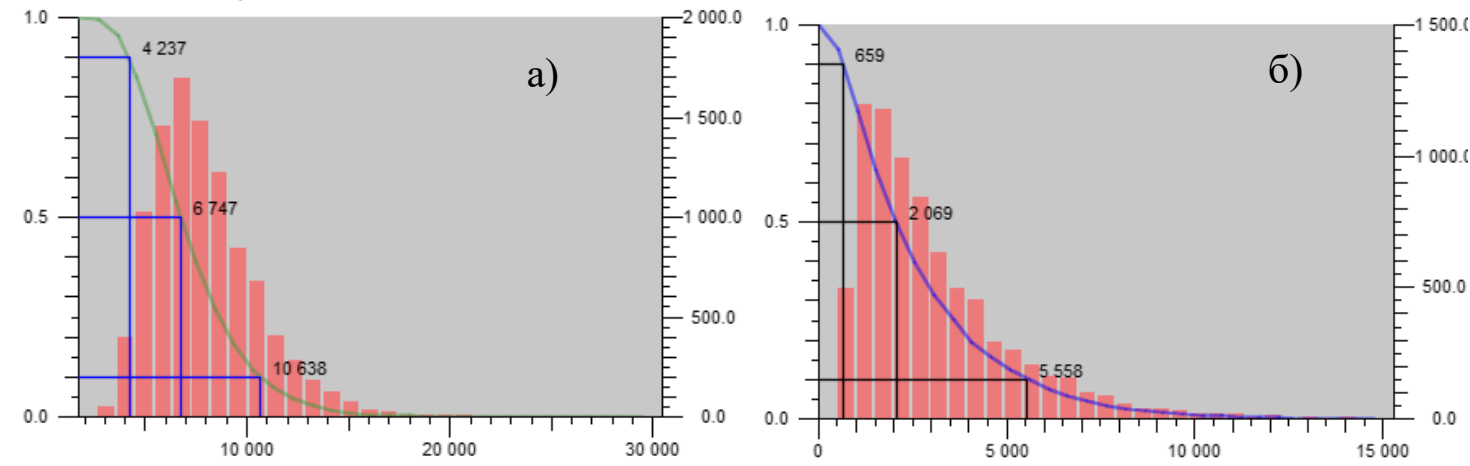

Рисунок 4 Распределения начальных геологических ресурсов без (а) и с (б) учёта gCoS

\section{Выводы}

- В рамках данной работы, выполнена вероятностная оценка ресурсов и оценка $\mathrm{gCoS}$ для объектов из краткосрочной программы ГРР. После проведения ГРР будет возможно оценить правильность выбора коэффициентов и скорректировать методический подход.

- Наиболее перспективен объект 1, т.к. чем больше пластов, тем выше шанс получить нефть в 1 из них.

- Крайне важно верно оценить шанс геологического успеха, т.к. это позволяет оценить степень риска при ведении ГРР и влияет на экономическую привлекательность и успешность проекта.

- Использование $\mathrm{gCoS}$ позволяет избежать завышенных ожиданий, отказаться от заведомо неуспешных проектов, расставить приоритеты в существующей программе ГРР, оценить её эффективность и спланировать мероприятия, направленные на снижение рисков.

\section{Библиография}

П. Роуз [2011] Анализ рисков и управление нефтегазопоисковыми проектами

Dr. Shang-Yup Kim et. all [2000] The CCOP Guidelines for Risk Assessment of Petroleum Prospects 


\section{EAGE}

EUROPEAN

ASSOCIATION OF

ENGINEERS

References

P. Rose [2011] Risk Analysis and Management of Petroleum Exploration Ventures

Dr. Shang-Yup Kim et. all [2000] The CCOP Guidelines for Risk Assessment of Petroleum Prospects 